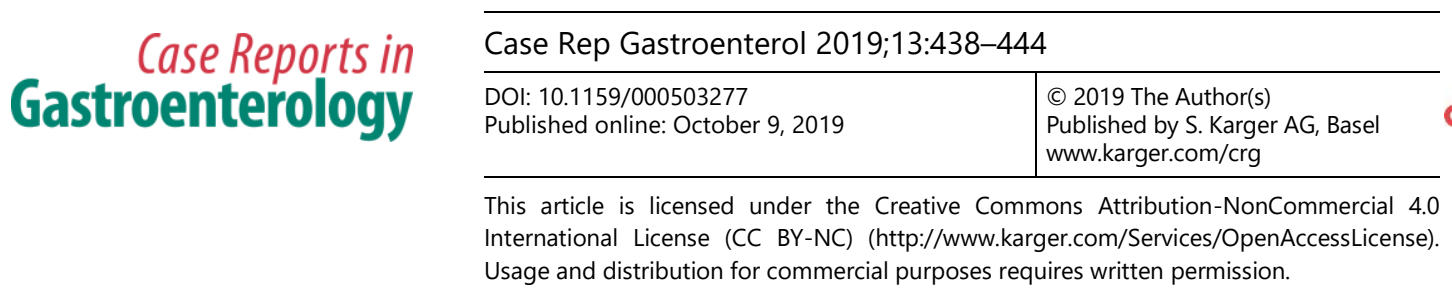

\title{
Biliary Fascioliasis in Chronic Calcific Pancreatitis Presenting with Ascending Cholangitis and Biliary Stricture
}

\author{
Tanawat Pattarapuntakul $^{\mathrm{a}}$ Bancha Ovartlarnporn ${ }^{\mathrm{a}} \quad$ Worapot Rojsanga $^{\mathrm{a}}$ \\ Thanaidpon Yungyoob \\ aNKC Institute of Gastroenterology and Hepatology, Songklanagarind Hospital, Faculty of \\ Medicine, Prince of Songkla University, Hat Yai, Thailand; 'bInternal Medicine, Shanghai \\ Medical College, Fudan University, Shanghai, China
}

\section{Keywords}

Biliary fascioliasis · Common bile duct obstruction · Ascending cholangitis

\begin{abstract}
Biliary fascioliasis is a rare infection of the hepatobiliary system. In human, it is known to present with two main phases; acute phase (hepatic phase) presenting with abdominal pain or abnormal liver biochemistry then chronic phase (biliary phase) presenting with biliary obstruction or cholangitis. Optimal treatment of biliary fascioliasis consists of endoscopic retrograde cholangiography with removal of the parasite and single oral dose of triclabendazole. We report a rare case of biliary fascioliasis in chronic calcified pancreatitis who presented with ascending cholangitis and biliary stricture. A 63-years-old Thai man was referred to our hospital for treatment of clinical symptoms severe cholangitis. Magnetic resonance cholangiopancreatography showed evidence of distal common bile duct stricture associated with chronic calcific pancreatitis. ERCP was performed, that found a few amorphous filling defects in the common bile duct and distal biliary stricture. After removal of the foreign body of what seems to be a fluke parasite followed with single oral dose triclabendazole thereafter, the clinical symptom was improved dramatically.




\section{Case Reports in Gastroenterology}

Case Rep Gastroenterol 2019;13:438-444 DOI: $10.1159 / 000503277$

(c) 2019 The www.karger.com/crg

Pattarapuntakul et al.: Biliary Fascioliasis in Chronic Calcific Pancreatitis Presenting with Ascending Cholangitis and Biliary Stricture

\section{Introduction}

Biliary fascioliasis is a rare infection of the hepatobiliary system, caused by the trematode. Fasciola hepatica and Fasciola gigantica have been found in parts of Asia and Africa where both species are an endemic parasitic infection in the area with, human is an accidental hosts. It had recently become well-recognized worldwide and is becoming an important public health problem with an estimated of 2.5 million people infected in about 61 countries [1]. Fasciola spp. infection in humans has two main phases; acute phase (hepatic phase) presenting with abdominal pain or abnormal liver biochemistry due to the migration of larval fluke from the intestine to liver parenchyma penetrating through the Glisson's capsules causing inflammation and toxic reaction and chronic phase (biliary phase) presenting with biliary obstruction or cholangitis due to migration of the fluke from the venous system to the biliary tree. Biliary fascioliasis is difficult to diagnosed and needed multimodality and diagnostic approaches including radiology, endoscopy and histopathology. Optimal treatment consists of endoscopic retrograde cholangiography with removal the foreign body followed by single oral dose triclabendazole.

\section{Case Presentation}

A 63-year-old Thai man was referred to our hospital from a local government hospital in September 2018. He presented with acute intermittent epigastric pain and high-grade fever (body temperature $39^{\circ} \mathrm{C}$ ) for 5 days. He was diagnosed with acute cholangitis and had initially been treated with intravenous ceftriaxone and metronidazole for 5 days. The symptoms slightly improved, but he still had abdominal pain and persistent fever; he was then referred to our hospital. He had a history of alcoholic chronic pancreatitis and diabetes mellitus type 2 with insulin supplementation. He had a history of heavy alcohol drinking ( $80 \mathrm{~g}$ per day for 20 years) and active smoking (10 packs per year). There was no history intravenous drug use, blood transfusion and unprotected sexual intercourse as well as no family history of viral hepatitis or liver disease.

On physical examination, he appeared conscious, slightly pale without icteric sclera, with vital signs body temperature $39.3^{\circ} \mathrm{C}$, blood pressure $100 / 60 \mathrm{~mm} \mathrm{Hg}$, and pulse rate $100 / \mathrm{min}$. His abdomen was soft with tenderness at the right upper abdomen. Murphy's sign was negative. The liver size was about $10 \mathrm{~cm}$ with a firm consistency smooth surface and blunt edge without any sign of portal hypertension or chronic liver disease.

\section{Initial Investigation}

The complete blood count was as follows: WBC 5,650/mm3, PMN 54\%, Lymp 23\%, Eos 12\%; HB 11.1 g/dL, HCT 32.7\%, MCV 98.5 fL, Plt $400 \times 103 / \mu \mathrm{L}$.

The liver biochemistry test revealed the following: total bilirubin $1.30 \mathrm{mg} / \mathrm{dL}$ (normal range $0.2-1.2 \mathrm{mg} / \mathrm{dL}$ ), direct bilirubin $0.97 \mathrm{mg} / \mathrm{dL}$ (normal range $0-0.2 \mathrm{mg} / \mathrm{dL}$ ), aspartate aminotransferase $185 \mathrm{U} / \mathrm{L}$ (normal range 0-32 U/L), alanine aminotransferase $70 \mathrm{U} / \mathrm{L}$ (normal range 0-33 U/L), and alkaline phosphatase 1,225 U/L (normal range 39-117 U/L).

Viral hepatitis B and C profiles were negative.

Magnetic resonance imaging (MRI) with abdominal magnetic resonance cholangiopancreatography (MRCP) were performed; the resulting images showed abrupt change in caliber with a thickened wall of the distal common bile duct $2 \mathrm{~cm}$ in length caused by upstream bile duct dilatation with no obvious common bile duct stone or intra-ductal filling defect. Multiple 


\section{Case Reports in Gastroenterology}

Case Rep Gastroenterol 2019;13:438-444 DOI: 10.1159/000503277

(c) 2019 The Author(s). Published by S. Karger AG, Basel www.karger.com/crg

Pattarapuntakul et al.: Biliary Fascioliasis in Chronic Calcific Pancreatitis Presenting with Ascending Cholangitis and Biliary Stricture

small gallstones were detected without evidence of acute cholecystitis. Atrophic changes of pancreas with multiple pancreatic duct stones and main pancreatic dilatation were also observed (Fig. 1). Initially, the diagnosis was suspected to be distal common bile duct stricture and severe cholangitis without response to initial antibiotic. He was later referred to our hospital for endoscopic management.

Emergency ERCP was performed, which showed a dilated common bile duct $18 \mathrm{~mm}$ in diameter consisting of large irregular shape amorphous filling defect in the common bile duct (Fig. 2). Sphincterotomy was then performed, and during the procedure a basket and balloon catheter was used to aid the extraction foreign bodies, which were observed as a dead, nonmotile, leaf-shaped parasite seen in the duodenum (Fig. 3). After bile duct clearance, a biliary double-pigtail plastic stent $7 \mathrm{Fr} \times 5 \mathrm{~cm}$ was inserted for biliary drainage.

We investigated the serology test for Fasciola antibody, but the result was negative. The definite diagnosis was confirmed by histopathology of dead parasite (Fig. 4). The patient was treated with endoscopic removal of the dead parasite subsequent with single oral dose triclabendazole (10 mg/kg body weight/day). The clinical result was significantly improved without any relapse during the 1-year follow-up.

The patient came for the clinical follow-up, and an ERCP for removal of stent with complete occlusion cholangiography was done to confirm that there was no other filling defect in the extrahepatic bile duct and that the distal biliary stricture disappeared.

Liver biochemistry returned to normal: TB $0.50 \mathrm{mg} / \mathrm{dL}$ (normal range $0.2-1.2 \mathrm{mg} / \mathrm{dL}$ ); DB $0.25 \mathrm{mg} / \mathrm{dL}$ (normal range 0-0.2 mg/dl); aspartate aminotransferase $40 \mathrm{U} / \mathrm{L}$ (normal range 0-32 U/L); alanine aminotransferase $20 \mathrm{U} / \mathrm{L}$ (normal range $0-33 \mathrm{U} / \mathrm{L}$ ); and alkaline phosphatase $126 \mathrm{U} / \mathrm{L}$ (normal range 39-117 U/L).

\section{Discussion}

Biliary fascioliasis is a rare infection of the hepatobiliary system. Human is an accidental host where the infection cycle started from ingestion of contaminated water or vegetables containing the larvae [1]. Adult flukes of Fasciola spp. are flat worms measuring $2.0-4.0 \mathrm{~cm}$ in length and 1-1.5 cm in width. Fasciola spp. infection in humans has two main phases; acute phase (hepatic phase) presenting with abdominal pain or abnormal liver biochemistry due to the migration of larval fluke from the intestine to the liver parenchyma through the Glisson's capsule causing inflammation and toxic reaction, and chronic phase (biliary phase) presenting with biliary obstruction or cholangitis due to the migration of fluke from the venous system to the biliary tree, usually occurring 6 months after initial infection. Half of the patients are asymptomatic, and very few cases develop biliary tree obstruction, as in our patient [2]. The parasite itself can mechanically obstruct the bile duct, leading to secondary hyperplasia and hypertrophy of ductal epithelium due to the increase in the concentration of proline. As a result, periductal fibrosis and thickening of the duct walls occur causing biliary stricture [3].

The ultrasound imaging shows multiple hypoechoic content in the liver parenchyma with biliary dilatation with or without filling defect. The cross-sectional imaging (CT scan or MRI) shows additional finding of the liver nodules and capsular enhancement associated with biliary dilatation and filling defect, which sometimes may be confused with malignancy or bile duct stone [3, 4]. The MRCP may also show biliary dilatation and filling defect [5]. The most useful diagnostic test for viewing the bile ducts is cholangiography by ERCP. Some technical radiology limitations make bile duct detail obtained by ultrasound, CT or MRCP imaging methods inferior to that obtained with ERCP. For this reason, ERCP is considered to be the gold 
standard for bile duct imaging and is considered the first choice in patients with biliary fascioliasis [6-8].

The serology test for Fasciola infection in humans has been used to detect antigen or antibodies. The antigen can be detected in the serum of the patients, where most of the circulating antigens have an immune complex form. Utilizing polyclonal antibodies against proteins in a sandwich ELISA system for the diagnosis of human fascioliasis achieved a diagnostic efficacy of $95.52 \%$ for coproantigen (sensitivity of $96.4 \%$ and specificity of 94.8 ) and $87.93 \%$ (sensitivity of $94.74 \%$ and specificity of $84.62 \%$ ) for detecting circulating antigen. A dotELISA, using the $27-\mathrm{kDa}$ antigen of Fasciola gigantica, had $98.2 \%$ sensitivity and $100 \%$ specificity in the diagnosis of human fascioliasis [9].

Treatment of human fascioliasis is difficult. Single oral dose of triclabendazole $(10 \mathrm{mg} / \mathrm{kg}$ body weight/day) is the drug of choice for its effectiveness against both adult and immature worms [10]. The mechanism of the drug involves an inhibitory effect on Fasciola hepatica synthesis of its tegumental ultra-structure with an active sulfoxide metabolite [11]. This treatment is reportedly effective in about $80-90 \%$ of patients and is well tolerated [12]. The biliary phase involves a combination of ERCP with removal of all foreign body in the biliary tract and medication.

We reported a rare case of a multiple intraductal dead Fasciola hepatica causing severe ascending cholangitis and distal biliary stricture. Successful treatment was achieved by endoscopic removal the fluke followed by single oral dose triclabendazole.

\section{Acknowledgements}

The authors would like to thank Dr. Naruemon Wisedopas for reviewing and taking a photo of the parasite specimen, and Dr. Teeravut Tubtawee for reviewing the MRI and MRCP imaging and helping us to complete data collection for this case report.

\section{Statement of Ethics}

This case report was approved by the Ethic Committees of Faculty of Medicine, Prince of Songkla University, and written informed consent was obtained from the patient. The committees use Declaration of Helsinki ethical principles and the International Conference on Harmonization in Good Clinical Practice.

Written informed consent was obtained from the patient for publication of this case report and any accompanying images. A copy of the written consent is available for review by the Editor-in-Chief of this Journal.

\section{Disclosure Statement}

The authors declare that they have no competing interests.

\section{Funding Sources}

None. 


\section{Case Reports in Gastroenterology}

\section{Author Contributions}

T.P. and W.R. were responsible for the study concept and design, data collection, discussion, conclusion, and drafting of the manuscript. T.P. and T.Y. reassessed the contents and English grammar of the manuscript. T.P. and B.O. supervised the whole process of the study. All authors read and approved the final manuscript.

\section{References}

1 Gulsen MT, Savas MC, Koruk M, Kadayifci A, Demirci F. Fascioliasis: a report of five cases presenting with common bile duct obstruction. Neth J Med. 2006 Jan;64(1):17-9.

2 Hosseini G, Sarkari B, Moshfe A, Motazedian MH, Abdolahi Khabisi S. Epidemiology of Human Fascioliasis and Intestinal Helminthes in Rural Areas of Boyer-Ahmad Township, Southwest Iran; A Population Based Study. Iran J Public Health. 2015 Nov;44(11):1520-5.

3 Ha JS, Choi HJ, Moon JH, Lee YN, Tae JW, Choi MH, et al. Endoscopic Extraction of Biliary Fascioliasis Diagnosed Using Intraductal Ultrasonography in a Patient with Acute Cholangitis. Clin Endosc. 2015 Nov;48(6):579-82.

4 Koç Z, Ulusan S, Tokmak N. Hepatobiliary fascioliasis: imaging characteristics with a new finding. Diagn Interv Radiol. 2009 Dec;15(4):247-51.

5 Dadhwal US, Kumar V. Benign bile duct strictures. Med J Armed Forces India. 2012 Jul;68(3):299-303.

6 Osman M, Lausten SB, El-Sefi T, Boghdadi I, Rashed MY, Jensen SL. Biliary parasites. Dig Surg. 1998;15(4):287-96.

7 Dowidar N, El Sayad M, Osman M, Salem A. Endoscopic therapy of fascioliasis resistant to oral therapy. Gastrointest Endosc. 1999 Sep;50(3):345-51.

8 Veerappan A, Siegel JH, Podany J, Prudente R, Gelb A. Fasciola hepatica pancreatitis: endoscopic extraction of live parasites. Gastrointest Endosc. 1991 Jul-Aug;37(4):473-5.

9 Sarkari B, Khabisi SA. Immunodiagnosis of Human Fascioliasis: An Update of Concepts and Performances of the Serological Assays. J Clin Diagn Res. 2017 Jun;11(6):0E05-10.

10 Karabuli TA, Shaikhani MA, Karadaghi SH, Kasnazan KH. Education and imaging. Hepatobiliary and pancreatic: fascioliasis. J Gastroenterol Hepatol. 2009 Jul;24(7):1309.

11 Wilkinson M, Horackova M, Giles A. Reduction of ventricular M2 muscarinic receptors in cardiomyopathic hamster (CHF 147) at the necrotic stage of the myopathy. Pflugers Arch. 1994 Apr;426(6):516-23.

12 López-Vélez R, Domínguez-Castellano A, Garrón C. Successful treatment of human fascioliasis with triclabendazole. Eur J Clin Microbiol Infect Dis. 1999 Jul;18(7):525-6. 


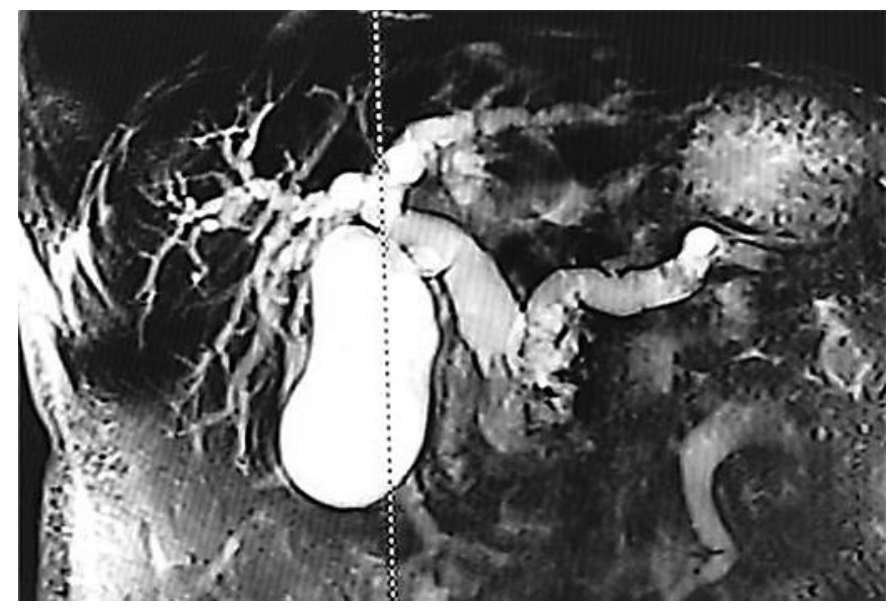

Fig. 1. MRCP showed abrupt change in the caliber and wall thickening at the distal common bile duct with upstream bile duct dilatation. No obvious common bile duct stone or intra-ductal filling defect. Multiple pancreatic duct stones and main pancreatic dilatation were observed.

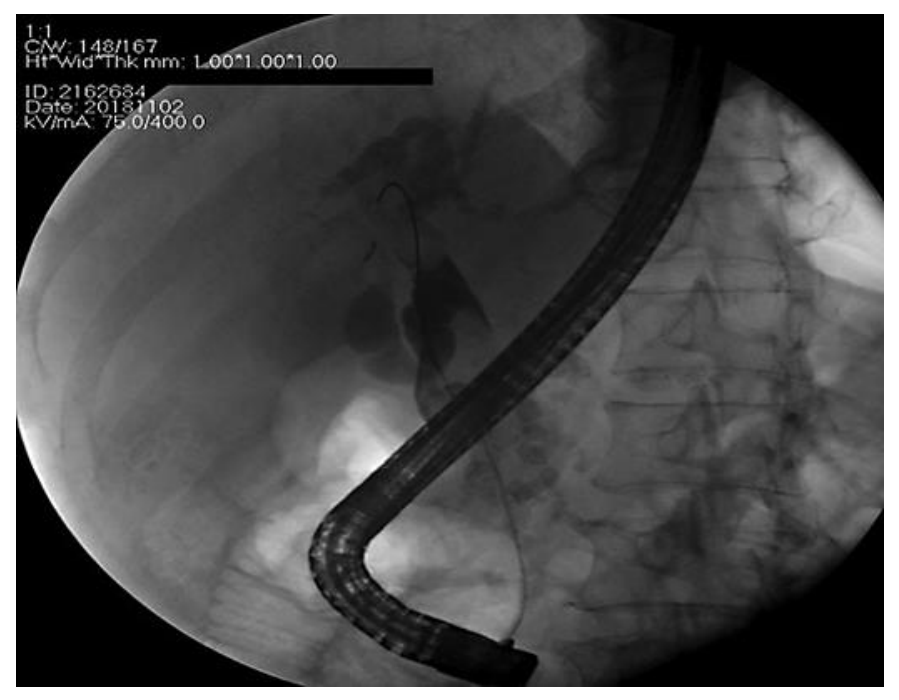

Fig. 2. Cholangiography showed a large irregular shape amorphous filling defect in the dilated common bile duct. 


\section{Case Reports in \\ Gastroenterology}

Case Rep Gastroenterol 2019;13:438-444

DOI: $10.1159 / 000503277$

(c) 2019 The Author(s). Published by S. Karger AG, Basel www.karger.com/crg

Pattarapuntakul et al.: Biliary Fascioliasis in Chronic Calcific Pancreatitis Presenting with Ascending Cholangitis and Biliary Stricture

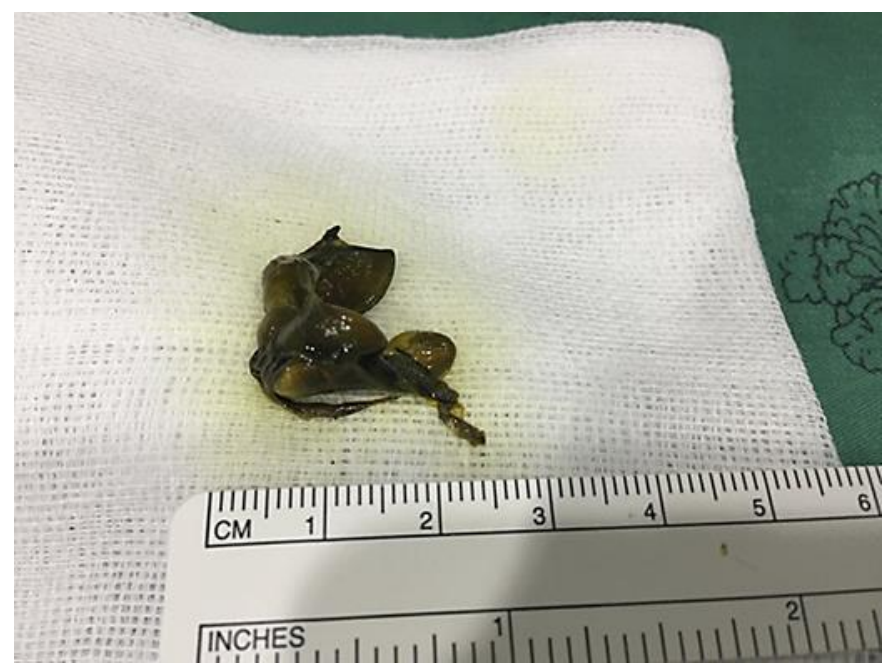

Fig. 3. Gross specimen showing a dead, non-motile, leaf-shaped parasite after extraction from the common bile duct.

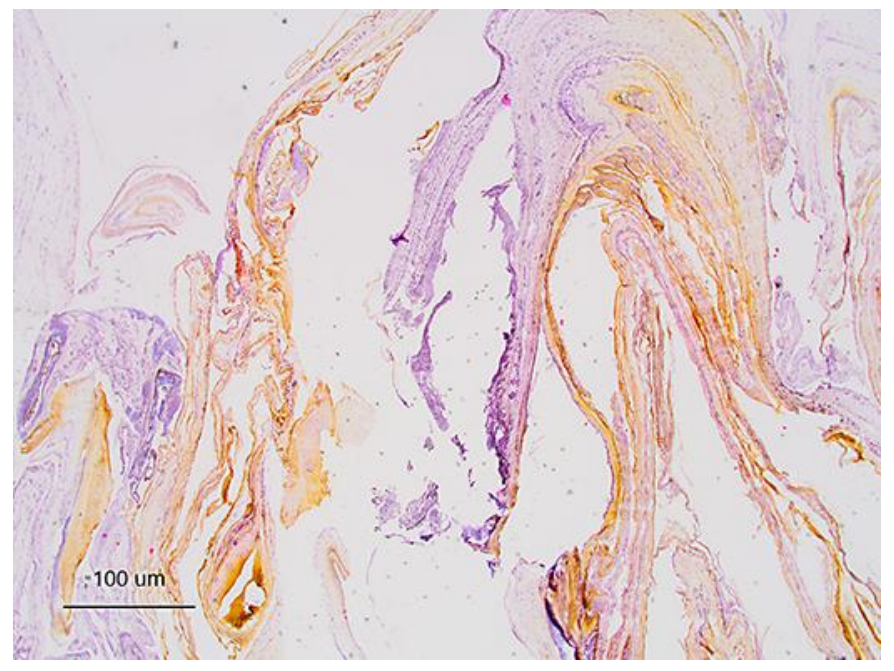

Fig. 4. Histopathology showing a carmine stain of a body part of Fasciola spp. 